(c) Springer Science+Business Media New York 2012 aiminsang@163.com; larry017@163.com. 
Feng Guijuan,

Department of Gastroenterology and Hepatology, Affiliated Hospital of Nantong University, Nantong, Jiangsu Province 226001, People's Republic of China

Sang Aimin, and

Department of Ophthalmology, Affiliated Hospital of Nantong University, Nantong, Jiangsu

Province 226001, People's Republic of China

\section{Li Liren}

Department of Gastroenterology and Hepatology, Affiliated Hospital of Nantong University, Nantong, Jiangsu Province 226001, People's Republic of China

\# These authors contributed equally to this work.

\section{Abstract}

Recent studies have shown that mesenchymal stem cells (MSCs) are expected to become promising therapeutic agents for the treatment of diabetic retinopathy (DR); moreover, we previously demonstrated that bone marrow (BM)-MSCs from nonobese diabetic (NOD) mice (an ideal DR model) had abnormal migration and adhesion. So, we hypothesized that NOD-MSCs also have abnormal retinal neuron-like differentiation potential. MSCs were cultured with brainderived neurotrophic factor, nerve growth factor, and basic fibroblast growth factor. Western blot analysis and immunofluorescence both showed that the level of retinal neuron-like markers, such as glial fibrillary acidic protein, neuron-specific nuclear protein, tyrosine hydroxy-lase, Thy-1, glutamine synthetase, and rhodopsin was lower in NOD-MSCs than in imprinting control region MSCs. Furthermore, we explored the precise mechanisms controlling this change in NOD-MSCs. The expression levels of some important member proteins in $\mathrm{Wnt} / \beta$-catenin signaling were determined and suggested the downregulation of $\mathrm{Wnt} / \beta$-catenin signaling with retinal neuron-like differentiation of NOD-MSCs. Incubation of NOD-MSCs in medium supplemented with human recombinant Wnt1 resulted in a significant upregulation of retinal neuron-like markers, and the effects of Wnt 1 were dose-dependent. Taken together, our study indicated that the inhibition of $\mathrm{Wnt} / \beta$-catenin signaling in NOD-MSCs after induction could contribute to the abnormal retinal neuron-like differentiation. These data provide important preclinical references supporting the basis for further development of autologous MSC-based therapies for DR.

\section{Keywords}

BM-MSCs; Diabetic retinopathy; NOD mice; Wnt/B-catenin signaling; Differentiation

\section{Introduction}

Diabetic retinopathy (DR) is a common complication of diabetes and a leading cause of legal blindness in working-age adults (Fong et al. 2004). During the first two decades of disease, nearly all patients with type 1 diabetes mellitus (T1DM) and over $60 \%$ of patients with type 2 diabetes mellitus develop DR. During recent years, much of the research has been focused on vascular changes, including increased vascular permeability, leading to edema, and endothelial cell proliferation, but it is becoming apparent that the 
neurodegenerative changes occur beyond the vascular cells of the retina. The diabetesassociated pathological changes lead to neuronal apoptosis, glial cell reactivity, microglial activation, and their normal interactions, which occur earlier than the effects on endothelial cells (Barber 2003; Gardner et al. 2002). Recently, a significant number of trials have shown promising results in using mesenchymal stem cells (MSCs) for the treatment of diabetes mellitus (Tsai et al. 2012; Ho et al. 2012) and DR (Volarevic et al. 2011; Yang et al. 2010).

MSCs are multipotent, self-renewing cells that can be found in almost all postnatal organs and tissues (Perin et al. 2007; Rada et al. 2011; Lee et al. 2004b; Wang et al. 2004). The main functional characteristics of MSCs are their immunomodulatory ability, capacity for self-renewal, and differentiation into mesodermal tissues. Notably, several studies have suggested that MSCs have the capacity to differentiate into neural cells, such as neurons, astrocytes, and oligodendrocytes in vitro (Porada et al. 2006; Chamberlain et al. 2007). Furthermore, through differentiation into photoreceptor and glial-like cells in the retina, transplanted MSCs improved the integrity of the blood-retinal barrier, thus ameliorating DR in streptozotocin diabetic rats (Yang et al. 2010). Because of their differentiation capacity, MSCs are expected to become promising therapeutic agents for the improvement of retina function and treatment of DR.

The nonobese diabetic (NOD) mouse is an ideal model of spontaneous autoimmune disease resembling human T1DM ( $\mathrm{Li}$ et al. 2011). In the NOD T1DM model, mice spontaneously develop progressive insulitis beginning at 2 weeks of age, leading to diabetes onset by $16-$ 20 weeks of age (Szanya et al. 2002). After 4 weeks of onset of diabetes, retinal capillary basement membrane thickening begins. Perivascular edema and pericytes, endothelial cells, and ganglion cells apoptosis can also be found in NOD mice. The pathological process becomes more obvious in the 12th week of diabetes. So, the NOD mouse is also a useful and important model of DR ( $\mathrm{Li}$ et al. 2006). We previously demonstrated that bone marrow (BM)-MSCs from NOD mice had abnormal migration and adhesion. Suppression of PI3KAkt signaling might account for these abnormalities (Li et al. 2011). Surprisingly, administration of allogeneic BALB/c-MSC showed promising results in temporarily reversing hyperglycemia in new-onset diabetic NOD mice. But transfer of autologous NODMSCs imparted no such therapeutic benefit (Fiorina et al. 2009). Taken collectively, because NOD-MSCs are observed to have abnormal characteristics in previous studies, high efficiency of MSCs differentiation into neuron-like cells for example seems unlikely.

In the current study, we firstly investigated whether BM-MSCs from NOD mice could effectively differentiate into retinal cells by using a cocktail of brain-derived neurotrophic factor (BDNF), nerve growth factor (NGF), and basic fibroblast growth factor (bFGF), which could induce MSCs differentiation into retinal neuron-like cells (Tomita et al. 2006; Mori et al. 2005). To determine the effects of $\mathrm{Wnt} / \beta$-catenin signaling on neuron-like differentiation of NOD-MSCs, the expression of $\beta$-catenin, glycogen synthase kinase- $3 \beta$ (GSK-3ß), c-myc, and cyclin D1 were examined. Together with our data, we hypothesized that, compared with nondiabetic donors, BM-MSCs from NOD mice had low efficiency in differentiating into retinal neuron-like cells. These data provide important preclinical references supporting the basis for further development of autologous MSC-based therapies for DR. 


\section{Materials and Methods}

\section{Mice}

NOD mice (Slyke Experimental Animals Company, Shanghai, China) were bred in the animal house of Nantong University. Mice were housed by pairs in plastic cages under a pathogen-free environment, with continuous access to food and water on a 12-h light/dark cycle. The investigation was permitted by the Law of the People's Republic of China on the Protection of Wildlife, and the protocol was approved by the Institutional Animal Care Committee from Nantong University, China. NOD mice were generated by inbreeding of imprinting control region (ICR) and ICR mice in 1980. So, we used ICR mice for the control group. The inclusion criteria of NOD mice were the following: (1) Blood glucose levels: Mice were considered to be diabetic when nonfasting blood glucose levels were $>16.67$ $\mathrm{mmol} / \mathrm{L}$ using whole blood collected from the tail vein; (2) Gender: Only females were used in the studies because disease progression in males was slower and less consistent (Caldwell et al. 2005); (3) Age: NOD mice and ICR mice were both between 18 and 22 weeks.

\section{MSCs Culture and Identification}

To generate MSCs, BM mononuclear cells were isolated from the femurs and tibiae of at least five mice to minimize cell variability. The femurs and tibiae were removed from the NOD mice and BM was flushed out of the bones using $10 \mathrm{ml}$ phosphate-buffered saline (PBS) with $100 \mathrm{U} / \mathrm{ml}$ heparin in a syringe. The cells were centrifuged at 1,000 rpm for 8 min. The cell pellet was resuspended in $10 \mathrm{ml}$ Dulbecco's modified Eagle's medium (DMEM; Gibco, Big Cabin, OK, USA) supplemented with $12 \%$ fetal bovine serum (Gibco, Big Cabin, OK, USA) and plated in a $25-\mathrm{cm}^{2}$ plastic flask (Corning Inc., Corning, NY, USA) to allow the MSCs to adhere. Cultures were maintained in a humidified atmosphere with $5 \% \mathrm{CO}_{2}$ at $37{ }^{\circ} \mathrm{C}$. The medium was replaced and nonadherent cells were removed after 3 days. The medium was completely replaced every 3 days. Approximately 7-10 days after seeding, the cells became nearly confluent. The adherent cells were released from the dishes with $0.25 \%$ trypsin (Gibco, Big Cabin, OK, USA) and seeded into new fresh culture flasks. All the experiments described below were performed using MSCs from the third to the fifth passage. By flow cytometric analysis, both ICR-MSCs and NOD-MSCs were observed to be negative for CD14, CD34, CD38, and CD45 and positive for CD29, CD44, CD166, and CD105 (data not show). Our previously reported expression pattern to identify MSCs showed the same result (Li et al. 2011).

\section{Retinal Neuron-Like Differentiation of MSCs}

To examine the differentiation of NOD-MSCs in vitro, MSCs were incubated with trypsin for $3 \mathrm{~min}$ to generate a single-cell suspension. Cells $\left(1 \times 10^{3}\right)$ were plated on eight-well poly-D-lysine/laminin-coated chamber slides (BD Biosciences, San Jose, CA, USA) in DMEM/F-12 medium supplemented with $2 \% \mathrm{~B} 27,2 \% \mathrm{~N} 2$ (both from PAA Laboratories, Coelbe, Germany), $25 \mathrm{ng} / \mathrm{ml}$ BDNF, $40 \mathrm{ng} / \mathrm{ml} \mathrm{NGF}$, and $25 \mathrm{ng} / \mathrm{ml} \mathrm{bFGF} \mathrm{(all} \mathrm{from} \mathrm{R \& D}$ Systems, Minneapolis, MN, USA). To determine the effects of Wnt/ $\beta$-catenin signaling in retinal neuron-like differentiation, MSCs were grown in retinal neuron-like differentiation medium in the presence and absence of recombinant human Wnt1 (10-400 ng/ml; Peprotec, Rocky Hill, NJ, USA). 


\section{Immunofluorescence}

BM-MSCs were fixed with $4 \%$ paraformaldehyde at 7 or 14 days after differentiating and the cells were blocked in $1 \%$ bovine serum albumin and $0.2 \%$ Triton X-100 (both from Sigma-Aldrich, St. Louis, MO, USA) and then incubated at $37{ }^{\circ} \mathrm{C}$ for $1 \mathrm{~h}$ with primary antibody to glial fibrillary acidic protein (GFAP; goat antimouse, 1:100, astrocyte marker; Santa Cruz Biotechnology, Santa Cruz, CA, USA), tyrosine hydroxylase (TH; goat antimouse, 1:200, neuron marker; Cell Signaling, Danvers, MA, USA), glutamine synthetase (GS; goat anti-mouse, 1:200, Müller glia cells marker; Cell Signaling, Danvers, MA, USA), neuron-specific nuclear protein (NeuN; rabbit antimouse, 1:200, neuron marker; Abcam, Boston, MA, USA), Thy-1 (rabbit antimouse, 1:200, retinal ganglion cells marker; Santa Cruz Biotechnology, Santa Cruz, CA, USA), rhodopsin (rabbit antimouse, 1:500, rod photoreceptor marker; Abcam, Boston, MA, USA), $\beta$-catenin (rabbit antimouse, 1:200; Cell Signaling, Danvers, MA, USA), and GSK-3 $\beta$ (goat antimouse, 1:200; Santa Cruz Biotechnology, Santa Cruz, CA, USA). Then, the cells were washed and incubated in the dark for $1 \mathrm{~h}$ at $37^{\circ} \mathrm{C}$ with goat antirabbit (cy3)-conjugated antibodies (1:300; ICN Cappel, Aurora, OH, USA) and mouse antigoat fluorescein isothiocyanate-conjugated antibodies (1:300; Dako, Carpinteria, CA, USA). After washing, the nuclei were counterstained with Hoechst. After washing and being mounted, the cells were examined under a fluorescence microscope.

\section{Western Blot Analysis}

To assay the $\beta$-catenin protein, cytoplasmic and nuclear proteins from cultured cells were prepared using NE-PER nuclear and cytoplasmic extraction reagents (Pierce Chemical Company, Rockford, IL, USA), respectively. $\beta$-Actin and $\beta$-tubulin were used as the internal control for the cytoplasmic and nuclear proteins. The total cellular protein was extracted through the following methods: The different MSCs treatment groups were washed in coldbuffered PBS and were then lysed in radioimmunoprecipitation assay buffer $(150 \mathrm{mM} \mathrm{NaCl}$, $1 \%$ Triton X-100, $0.5 \%$ NaDOD, $0.1 \%$ sodium dodecyl sulfate, and $50 \mathrm{mM}$ Tris, $\mathrm{pH} 8.0$ ). After centrifugation $(12,000 \mathrm{rpm}, 5 \mathrm{~min})$ at $4{ }^{\circ} \mathrm{C}$, the protein supernatant was transferred into new tubes. The protein concentration of the samples was determined with a bicinchoninic acid protein assay (Pierce Chemical Company, Rockford, IL, USA). A 40-mg sample of the total protein was resolved using $12.5 \%$ sodium dodecyl sulfate polyacrylamide gel electrophoresis and transferred onto polyvinylidene difluoride (Millipore, Billerica, MA, USA) membranes. The membranes were blocked with $5 \%$ nonfat milk at room temperature for $1 \mathrm{~h}$ in Tris-buffered saline containing Tween 20. Primary antibodies to detect GFAP (goat antimouse, 1:500; Santa Cruz Biotechnology, Santa Cruz, CA, USA), TH (goat antimouse, 1:500; Cell Signaling, Danvers, MA, USA), GS (goat antimouse, 1:500; Cell Signaling, Danvers, MA, USA), NeuN (rabbit antimouse, 1:800; Cell Signaling, Danvers, MA, USA), Thy-1 (rabbit antimouse, 1:500; Santa Cruz Biotechnology, Santa Cruz, CA, USA), rhodopsin (rabbit antimouse, 1:1,000; Abcam, Boston, MA, USA), $\beta$-catenin (rabbit antimouse, 1:500; Cell Signaling, Danvers, MA, USA), phosphorylated $\beta$-catenin (goat antimouse, 1:200; Cell Signaling, Danvers, MA, USA), GSK-3 $\beta$ (rabbit antimouse, 1:500; Santa Cruz Biotechnology, Santa Cruz, CA, USA), glyceraldehyde 3-phosphate dehydrogenase (GAPDH; rabbit antimouse, 1:500; Cell Signaling, Danvers, MA, USA), $\beta$ actin (rabbit antimouse, 1:500; Cell Signaling, Danvers, MA, USA), or $\beta$-tubulin (rabbit 
antimouse, 1:500; Cell Signaling, Danvers, MA, USA) were incubated overnight with the membranes at $4{ }^{\circ} \mathrm{C}$. Lastly, the membrane was incubated with second antibody mouse antigoat or goat anti-rabbit conjugated horseradish peroxidase (1:2,000; SouthernBiotech, Birmingham, AL, USA) for $2 \mathrm{~h}$ and visualized using an enhanced chemiluminescence system (Pierce Chemical Company, Rockford, IL, USA).

\section{Morphometry of Differentiated Cells}

To examine the differentiation potential of NOD-MSCs, quantitative morphometry was performed by a ratio of positive cells versus total number of cells in the culture and selected based on Hoechst labeling $(n=5)$. In this counting study, cells were plated on eight-well poly-D-lysine/laminin-coated chamber slides. Five of eight wells were randomly chosen (by a masked observer), and all cells in the wells were counted. NOD-MSCs and ICR-MSCs positive for retinal neuron-like markers (GFAP, NeuN, TH, Thy-1, GS, and rhodopsin) were counted after 2 weeks of induction.

\section{Statistical Analysis}

All experiments were performed at least in triplicate. All data were presented as the mean \pm standard deviation of the replicates. Significance testing was performed using oneway analysis of variance to compare data from different experimental groups. $P<0.05$ was considered statistically significant.

\section{Results}

The Low Retinal Neuron-Like Differentiation Potential in NOD-MSCs After BDNF, NGF, and bFGF Treatment

Western blot analysis was carried out to determine the effect of BDNF, NGF, and bFGF on MSCs. Both NOD-MSCs and ICR-MSCs without induction showed only weak GFAP, NeuN, and GS expression. (MSCs without treatment did not express TH, Thy-1, and rhodopsin). After 7 days of induction, MSCs showed increased expression of GFAP, NeuN, TH, Thy-1, GS, and rhodopsin. No obvious alterations of expressions were observed between NOD-MSCs and ICR-MSCs mice. Compared with NOD-MSCs, only a small increase in rhodopsin expression was observed in the ICR-MSCs ( $* P<0.05$; Fig. 1g, i). After 14 days of induction, the expressions of GFAP, NeuN, TH, Thy-1, GS, and rhodopsin were remarkably elevated on both NOD-MSCs and ICR-MSCs and very obvious alterations of expressions were observed between NOD-MSCs and ICR-MSCs. The levels of GFAP, NeuN, TH, Thy-1, GS, and rhodopsin were higher in ICR-MSCs $(91.71 \pm 4.9,79.37 \pm 5.3$, $62.41 \pm 2.9,85.72 \pm 3.98,92.81 \pm 4.18$, and $89.27 \pm 1.98 \%)$ than in NOD-MSCs $(78.21 \pm 4.23$, $52.73 \pm 2.46,36.53 \pm 1.65,51.38 \pm 3.68,44.35 \pm 2.59$, and $51.27 \pm 3.55 \%, * P<0.05$; Fig. 1).

To explore the significant differences between NOD-MSCs and ICR-MSCs, double immunofluorescent labeling was performed in NOD-MSCs and ICR-MSCs 14 days after induction. The immunofluorescence staining of GFAP and NeuN (Fig. 2a), TH and Thy-1 (Fig. 2b), GS and rhodopsin (Fig. 2c) in the NOD-MSCs had a low intensity compared with the ICR-MSCs. These findings were consistent with the results of Western blot analysis. 
To further examine the differentiation potential of NOD-MSCs, quantitative evaluation of differentiation into retinal neuron-like cells was carried out using cell counting as previously described. After 14 days of BDNF, NGF, and bFGF treatment, percentages of ICR-MSCs expressing NeuN, GFAP, TH, Thy-1, GS, and rhodopsin were 0.0186, 0.0195, 0.0135, $0.0175,0.0135$, and $0.0059 \%$, respectively. The rates of NeuN-, GFAP-, TH-, Thy-1-, GS-, and rhodopsin-positive cells from NOD-MSCs treated with BDNF, NGF, and bFGF were $0.0163,0.0182,0.0105,0.0145,0.0099$, and $0.0042 \%$, respectively ( ${ }^{*} P<0.05$; Fig. $2 \mathrm{~d}$ ). Taking these data together, we found that, compared with ICR-MSCs, NOD-MSCs had the lower retinal neuron-like differentiation potential after BDNF, NGF, and bFGF treatment.

\section{Inhibition of Wnt/B-Catenin Signaling in NOD-MSCs After BDNF, NGF, and bFGF Treatment}

As we know, Wnt/ $\beta$-catenin signaling has been shown to be crucial in regulating embryonic development, cell proliferation and motility, cell fate determination, and generation of cell polarity in adult mammals (Ling et al. 2009; Pinto and Clevers 2005; Reya and Clevers 2005). Some recent studies have shown that $\mathrm{Wnt} / \beta$-catenin signaling is involved in differentiation into neuron-like cells (Sánchez-Sánchez et al. 2010; Salero and Hatten 2007; Otero et al. 2004; Kuwabara et al. 2009; Joksimovic et al. 2012; Wei et al. 2012). To identify the expression of Wnt/ $\beta$-catenin signaling in NOD-MSCs, the $\beta$-catenin and phosphorylated $\beta$-catenin expressions in the NOD-MSCs and ICR-MSCs were examined by Western blot analysis. After induction, both NOD-MSCs and ICR-MSCs showed increased expression of $\beta$-catenin and phosphorylated $\beta$-catenin. But at the 7th and 14th day, decreased expression of $\beta$-catenin and increased expression of phosphorylated $\beta$-catenin were clearly detected in the NOD-MSCs compared with that of the ICR-MSCs $(* P<0.05$; Fig. 3a-c). The results indicated Wnt/ $\beta$-catenin signaling was decreased in NOD-MSCs after induction.

To better examine the relationship between $\mathrm{Wnt} / \beta$-catenin signaling and differentiation potential in the NOD-MSCs, we used Western blot analysis to evaluate changes in total and phosphorylated $\beta$-catenin expression in MSCs in response to Wnt1 stimulation. MSCs were cultured in neural induction medium in the presence or absence of different concentrations of Wnt1 for 14 days. The results suggested that only treatment with high Wnt1 concentrations (100 and $400 \mathrm{ng} / \mathrm{mL}$ ) significantly increased the expression of $\beta$-catenin and decreased the expression of phosphorylated $\beta$-catenin, of which the phosphorylation sites are in the amino terminal Ser/Thr site $\left({ }^{*} P<0.05,{ }^{\#} P<0.05 ;\right.$ Fig. $3 \mathrm{~d}$, e). These results suggested that Wnt 1 could elevate Wnt/ $\beta$-catenin signaling of NOD-MSCs.

It is noteworthy that, when Wnt ligands bind to the frizzled family of receptors, phosphorylation of $\beta$-catenin can be inhibited, causing $\beta$-catenin stabilization and translocation into the cellular nucleus. To further evaluate the nuclear translocation of $\beta$ catenin, nuclear and cytoplasmic protein fractions were extracted from neurally induced MSCs. Total $\beta$-catenin in the nucleus was significantly lower in NOD-MSCs than in ICRMSCs ( ${ }^{\#} P<0.05$; Fig. $\left.4 \mathrm{a}, \mathrm{c}\right)$. On the other hand, we failed to detect any change of total $\beta$ catenin in the cytoplasm between NOD-MSCs and ICR-MSCs (Fig. 4a, b). Furthermore, the immunofluorescence staining of $\beta$-catenin in the cellular nucleus of NOD-MSCs had a low intensity compared with that in the ICR-MSCs (Fig. 4f). These results indicated that 
translocation of $\beta$-catenin into the cellular nucleus was clearly decreased in the NOD-MSCs compared with that of the ICR mice.

To further examine the decreased nuclear accumulation of $\beta$-catenin in NOD-MSCs, we used Western blot analysis to evaluate changes in nuclear and cytoplasmic $\beta$-catenin expression in MSCs in response to Wnt1 stimulation. It was determined that Wnt1 concentrations $>100 \mathrm{ng} / \mathrm{mL}$ were sufficient to increase nuclear $\beta$-catenin expression, a significant increase from $40.41 \pm 5.11 \%$ of $\beta$-catenin expression presented in cultures treated with $10 \mathrm{ng} / \mathrm{mL}$ ( ${ }^{\#} P<0.05$; Fig. $4 \mathrm{~d}$, e). But there was no change of total $\beta$-catenin in the cytoplasm between NOD-MSCs and ICR-MSCs after different concentrations of Wnt1. The results of immunofluorescence were consistent with the results of Western blot analysis (Fig. 4f), which demonstrated that Wnt 1 could promote the nuclear translocation of $\beta$ catenin.

GSK-3 $\beta$ is a key enzyme in negatively regulating Wnt/ $\beta$-catenin signaling. The inhibition of $\mathrm{Wnt} / \beta$-catenin signaling in NOD-MSCs was further studied by determining GSK-3 $\beta$ expression. Compared with the ICR-MSCs, GSK-3 $\beta$ expression was evidently increased in the NOD-MSCs ( ${ }^{\#} P<0.05$; Fig. 5a-c). However, after treatment with Wnt1, GSK-3 $\beta$ expression was significantly decreased, and the effects of Wnt 1 were dose-dependent ( ${ }^{P}<0.05$; Fig. 5a-e).

To further examine the expression of the target gene of Wnt/ $/$-catenin signaling, we detected the expression of c-myc and cyclin D1 by Western blot analysis. After treatment with neural induction medium, the expression of c-myc and cyclin D1 in the NOD-MSCs was significantly lower than that in the ICR-MSCs $\left({ }^{\#} P<0.05\right.$; Fig. 6a-c). However, after treatment with Wnt1, c-myc and cyclin D1 expression were significantly increased, and the effects of Wnt1 were dose-dependent ( ${ }^{\#} P<0.05,{ }^{\$} P<0.05$; Fig. 6d, e). These data further indicated that $\mathrm{Wnt} / \beta$-catenin signaling could be inhibited in NOD-MSCs after induction.

\section{Wnt1 Could Enhance MSCs Differentiation into Retinal Neuron-Like Cells}

Till now, we have found that Wnt/ $/$-catenin signaling could be inhibited in NOD-MSCs. Since canonical Wnt ligands have been proved as a significant agonist of neuronal differentiation, we investigate whether Wnt1 can upregulate retinal neuron markers in NODMSCs after induction. Firstly, Western blot analysis was used to investigate retinal neuronlike markers (GFAP, NeuN, TH, Thy-1, GS, and rhodopsin) expressions of MSCs in neural induction medium supplemented with human recombinant Wnt1 (10-400 ng/ml) for 14 days. From Fig. 7a, c, these protein expressions revealed similar change trends. Wnt1 caused a distinct increase in expression levels of GFAP, NeuN, and TH $\left({ }^{\#} P<0.05\right.$, ${ }^{*} P<0.05,{ }^{\$} P<0.05$; Fig. $7 \mathrm{c}$ ) and Thy-1, GS, and rhodopsin $\left({ }^{\#} P<0.05, * P<0.05,{ }^{\$} P<0.05\right.$; Fig. $7 \mathrm{~d})$. Secondly, using immunofluorescence, we detected the expression levels of retinal neuron-like markers. Compared with NOD-MSCs in the absence of Wnt1, incubation of NOD-MSCs in medium supplemented with human recombinant Wnt $1(400 \mathrm{ng} / \mathrm{ml})$ for 14 days resulted in a more significant increase in the levels of immunofluorescent intensity of these retinal neuron-like markers (Fig. 7e, f). Thirdly, to further examine the roles of Wnt/Bcatenin signaling in retinal neuron-like differentiation of NOD-MSCs, quantitative evaluation of differentiation into retinal neuron-like cells was carried out using cell counting 
as previously described. After 14 days of human recombinant Wnt1 $(400 \mathrm{ng} / \mathrm{ml})$ treatment, percentages of NOD-MSCs expressing NeuN, GFAP, TH, Thy-1, GS, and rhodopsin were $0.0179,0.0192,0.0130,0.0172,0.0127$, and $0.0053 \%$, respectively. The rates of NeuN-, GFAP-, TH-, Thy-1-, GS-, and rhodopsin-positive cells from NOD-MSCs treated without human recombinant Wnt1 $(400 \mathrm{ng} / \mathrm{ml})$ were $0.0163,0.0182,0.0105,0.0145,0.0099$, and $0.0042 \%$, respectively $(* P<0.05 ;$ Fig. $7 \mathrm{~g}$ ). So, the immunofluorescence results supported the previous Western blotting data, indicating that the activation of $\beta$-catenin signaling induced by Wnt 1 obviously prevented retinal neuron-like differentiation in NOD-MSCs.

\section{Discussion}

DR is a major cause of visual impairment and the leading cause of blindness in the USA for individuals of 20-75 years of age (Kempen et al. 2004). MSCs have been developed and investigated nowadays as clinically applicable cell sources for tissue engineering and gene therapy because of their multipotency, ease of isolation, and ready availability. During recent years, many studies have shown that MSCs have been identified to have the potential to engraft and differentiate into neuron-like cells both in vivo and in vitro and may also provide an option to retinal injury and disease repairing (Yang et al. 2010; Cao et al. 2005; Safford et al. 2002). These novel data indicate that MSCs could be a component of an innovative and successful cell-based regimen for DR treatment. But recently, our study showed that BM-MSCs from NOD mice had abnormal migration and adhesion (Li et al. 2011). In addition, administration of allogeneic BALB/c-MSCs showed promising results in temporarily reversing hyperglycemia in new-onset diabetic NOD mice. But transfer of autologous NOD-MSCs imparted no such therapeutic benefit (Fiorina et al. 2009). In view of the abnormality of autologous NOD-MSCs both in vivo and in vitro, we hypothesize that autologous NOD-MSCs have the abnormal retinal neuron-like differentiation potential.

In this study, to determine the retinal neuron-like differentiation of BM-MSCs in NOD mice, we chose a cocktail of BDNF, NGF, and bFGF. Compared with ICR-MSCs, NOD-MSCs had the lower retinal neuron-like differentiation potential after induction. Western blot analysis, immunofluorescence, and quantitative evaluation showed that the level of retinal neuron-like markers (GFAP, NeuN, TH, Thy-1, GS, and rhodopsin) was lower in NODMSCs than in ICR-MSCs. These studies demonstrated that, compared with ICR-MSCs, NOD-MSCs had lower retinal neuron-like differentiation potential after BDNF, NGF, and bFGF treatment.

Wnt/ $\beta$-catenin signaling is activated by the binding of Wnt ligands to the frizzled family of receptors. In the absence of Wnt ligands, $\beta$-catenin is phosphorylated by GSK-3 $\beta$ and then degraded by the ubiquitin-proteasome system. When Wnt ligands bind to frizzled receptors, GSK-3 $\beta$ activity is inhibited and unphosphorylated $\beta$-catenin accumulates in the cytoplasm and translocates into the nucleus, where it promotes the transcription of a variety of target genes (such as c-myc and cyclin D1) (Clevers 2006). Several lines of evidence suggest that $\mathrm{Wnt} / \beta$-catenin signaling plays pivotal roles in cell fate specification in the nervous systems. Canonical Wnt signaling allows $\beta$-catenin to translocate to the nucleus, where it interacts with the $\mathrm{T}$ cell factor family of DNA-binding proteins and regulate transcription (Logan and Nusse 2004; Grigoryan et al. 2008; Toledo et al. 2008). Neural crest progenitor cells were 
shown to acquire Brn3a expression at the expense of Sox 10 expression by $\mathrm{Wnt} / \beta$-catenin signaling (Hari et al. 2002; Lee et al. 2004a). Furthermore, accumulating studies have indicated that $\mathrm{Wnt} / \beta$-catenin signaling has also been shown to promote neuronal differentiation from embryonic, somatic, and neural stem cells or progenitors (SánchezSánchez et al. 2010; Salero and Hatten 2007; Otero et al. 2004; Kuwabara et al. 2009; Joksimovic etal. 2012; Wei etal. 2012). In Xenopus, canonical Wnt signaling in progenitor cells at the peripheral margin of the retina promotes neurogenesis (Van Raay et al. 2005). Based on these results, we explored the mechanisms of $\mathrm{Wnt} / \beta$-catenin signaling on retinal neuron-like differentiation of NOD-MSCs.

Although considerable evidences now suggest that Wnt/ $\beta$-catenin signaling can promote neural differentiation, further research is needed to examine the expression of $\mathrm{Wnt} / \beta$-catenin signaling in NOD-MSCs. From our results, immunofluorescence and Western blot data showed that the expression of $\beta$-catenin and the target gene of $\mathrm{Wnt} / \beta$-catenin signaling (cmyc and cyclin D1) in NOD-MSCs were lower than that in ICR-MSCs, but the phosphorylated $\beta$-catenin and GSK-3 $\beta$ expressions were higher in NOD-MSCs at the 7 th and 14 th day after induction. These results suggested that Wnt/ $\beta$-catenin signaling could be inhibited in NOD-MSCs after induction. A previous study showed that Wnt1, when combined with neural induction medium, could upregulate the expression of $\mathrm{Wnt} / \beta$-catenin signaling and then could promote neuronal differentiation from BM-MSCs (Kondo et al. 2011). It was interesting to note that, after treatment with Wnt1 for 14 days, decreased expression of phosphorylated $\beta$-catenin and GSK-3 $\beta$ and increased expression of $\beta$-catenin, $c$-myc, and cyclin D1 were clearly detected in the NOD-MSCs. In addition, total $\beta$-catenin in the nucleus was significantly increased in NOD-MSCs. Furthermore, the activation of $\beta$ catenin signaling induced by Wnt1 obviously prevented retinal neuron-like differentiation. The effects of Wnt1 were all dose-dependent. These studies demonstrated that the inhibition of Wnt/ $\beta$-catenin signaling in NOD-MSCs after treatment could contribute to the abnormal retinal neuron-like differentiation.

In conclusion, we believe that our data provide a basis for the development of a cell-based therapy for which, compared with diabetic donors, MSCs from nondiabetic donors have the more effective retinal neuron-like differentiation potential and could be isolated and administered to patients for the prevention and reversal of DR. Indeed, the translation of this knowledge into clinical practice could eventually transform the overall strategy we use to treat this disease.

\section{Acknowledgments}

This work was supported by Natural Science Foundation of China, Grant (No.81172841), Natural Science Foundation of Jiangsu Colleges and Universities Grant (09KJB320010) (10KJB320012); “Top Six Types of Talents" Financial Assistance of Jiangsu Province Grant (No. 6 and NO.7), Jiangsu province's outstanding medical academaic leader program (LJ201136); Graduate Student Innovation of Science and Technology Projects in Jiangsu Province and in Nantong University (Grants No.13025045).

\section{References}

Barber AJ. A new view of diabetic retinopathy: a neurodegenerative disease of the eye. Prog Neuropsychopharmacol Biol Psychiatry. 2003; 27:283-290. [PubMed: 12657367] 
Caldwell RB, Bartoli M, Behzadian MA, El-Remessy AE, Al-Shabrawey M, Platt DH, Liou GI, Caldwell RW. Vascular endothelial growth factor and diabetic retinopathy: role of oxidative stress. Curr Drug Targets. 2005; 6:511-524. [PubMed: 16026270]

Cao Y, Sun Z, Liao L, Meng Y, Han Q, Zhao RC. Human adipose tissue-derived stem cells differentiate into endothelial cells in vitro and improve postnatal neovascularization in vivo. Biochem Biophys Res Commun. 2005; 332:370-379. [PubMed: 15896706]

Chamberlain G, Fox J, Ashton B, Middleton J. Concise review: mesenchymal stem cells: their phenotype, differentiation capacity, immunological features, and potential for homing. Stem Cells. 2007; 25:2739-2749. [PubMed: 17656645]

Clevers H. Wnt/beta-catenin signaling in development and disease. Cell. 2006; 127:469-480. [PubMed: 17081971]

Fiorina P, Jurewicz M, Augello A, Vergani A, Dada S, La Rosa S, Selig M, Godwin J, Law K, Placidi C, Smith RN, Capella C, Rodig S, Adra CN, Atkinson M, Sayegh MH, Abdi R. Immunomodulatory function of bone marrow-derived mesenchymal stem cells in experimental autoimmune type 1 diabetes. J Immunol. 2009; 183:993-1004. [PubMed: 19561093]

Fong DS, Aiello L, Gardner TW, King GL, Blankenship G, Cavallerano JD, Ferris FL 3rd, Klein R. Retinopathy in diabetes. Diab Care. 2004; 27(Suppl 1):S84-S87.

Gardner TW, Antonetti DA, Barber AJ, LaNoue KF, Levison SW. Diabetic retinopathy: more than meets the eye. Surv Ophthalmol. 2002; 47(Suppl 2):S253-S262. [PubMed: 12507627]

Grigoryan T, Wend P, Klaus A, Birchmeier W. Deciphering the function of canonical Wnt signals in development and disease: conditional loss- and gain-of-function mutations of beta-catenin in mice. Genes Dev. 2008; 22:2308-2341. [PubMed: 18765787]

Hari L, Brault V, Kleber M, Lee HY, Ille F, Leimeroth R, Paratore C, Suter U, Kemler R, Sommer L. Lineage-specific requirements of beta-catenin in neural crest development. J Cell Biol. 2002; 159:867-880. [PubMed: 12473692]

Ho JH, Tseng TC, Ma WH, Ong WK, Chen YF, Chen MH, Lin MW, Hong CY, Lee OK. Multiple intravenous transplantations of mesenchymal stem cells effectively restore long-term blood glucose homeostasis by hepatic engraftment and $\beta$-cell differentiation in streptozocin-induced diabetic mice. Cell Transplant. 2012; 21:997-1009. [PubMed: 22004871]

Joksimovic M, Patel M, Taketo MM, Johnson R, Awatramani R. Ectopic Wnt/beta-catenin signaling induces neurogenesis in the spinal cord and hindbrain floor plate. PLoS One. 2012; 7:e30266. [PubMed: 22276170]

Kempen JH, O'Colmain BJ, Leske MC, Haffner SM, Klein R, Moss SE, Taylor HR, Hamman RF. The prevalence of diabetic retinopathy among adults in the United States. Arch Ophthalmol. 2004; 122:552-563. [PubMed: 15078674]

Kondo T, Matsuoka AJ, Shimomura A, Koehler KR, Chan RJ, Miller JM, Srour EF, Hashino E. Wnt signaling promotes neuronal differentiation from mesenchymal stem cells through activation of Tlx3. Stem Cells. 2011; 29:836-846. [PubMed: 21374761]

Kuwabara T, Hsieh J, Muotri A, Yeo G, Warashina M, Lie DC, Moore L, Nakashima K, Asashima M, Gage FH. Wnt-mediated activation of NeuroD1 and retro-elements during adult neurogenesis. Nat Neurosci. 2009; 12:1097-1105. [PubMed: 19701198]

Lee HY, Kléber M, Hari L, Brault V, Suter U, Taketo MM, Kemler R, Sommer L. Instructive role of Wnt/beta-catenin in sensory fate specification in neural crest stem cells. Science. 2004a; 303:1020-1023. [PubMed: 14716020]

Lee OK, Kuo TK, Chen WM, Lee KD, Hsieh SL, Chen TH. Isolation of multipotent mesenchymal stem cells from umbilical cord blood. Blood. 2004b; 103:1669-1675. [PubMed: 14576065]

Li C, Xu Y, Jiang D, Hong W, Guo X, Wang P, Li W. The expression of HIF-1 in the early diabetic NOD mice. Yan Ke Xue Bao. 2006; 22:107-111. [PubMed: 17162888]

Li L, Xia Y, Wang Z, Cao X, Da Z, Guo G, Qian J, Liu X, Fan Y, Sun L, Sang A, Gu Z. Suppression of the PI3K-Akt pathway is involved in the decreased adhesion and migration of bone marrowderived mesenchymal stem cells from non-obese diabetic mice. Cell Biol Int. 2011; 35:961-966. [PubMed: 21449895]

Ling L, Nurcombe V, Cool SM. Wnt signaling controls the fate of mesenchymal stem cells. Gene. 2009; 433:1, 7. [PubMed: 19135507] 
Logan CY, Nusse R. The Wnt signaling pathway in development and disease. Annu Rev Cell Dev Biol. 2004; 20:781-810. [PubMed: 15473860]

Mori T, Kiyono T, Imabayashi H, Takeda Y, Tsuchiya K, Miyoshi S, Makino H, Matsumoto K, Saito H, Ogawa S, Sakamoto M, Hata J, Umezawa A. Combination of hTERT and bmi-1, E6, or E7 induces prolongation of the life span of bone marrow stromal cells from an elderly donor without affecting their neurogenic potential. Mol Cell Biol. 2005; 25:5183-5195. [PubMed: 15923633]

Otero JJ, Fu W, Kan L, Cuadra AE, Kessler JA. Beta-catenin signaling is required for neural differentiation of embryonic stem cells. Development. 2004; 131:3545-3557. [PubMed: 15262888]

Perin L, Giuliani S, Jin D, Sedrakyan S, Carraro G, Habibian R, Warburton D, Atala A, De Filippo RE. Renal differentiation of amniotic fluid stem cells. Cell Prolif. 2007; 40:936-948. [PubMed: 18021180]

Pinto D, Clevers H. Wnt control of stem cells and differentiation in the intestinal epithelium. Exp Cell Res. 2005; 306:357-363. [PubMed: 15925592]

Porada CD, Zanjani ED, Almeida-Porad G. Adult mesenchymal stem cells: a pluripotent population with multiple applications. Curr Stem Cell Res Ther. 2006; 1:365-369. [PubMed: 18220880]

Rada T, Reis RL, Gomes ME. Distinct stem cells subpopulations isolated from human adipose tissue exhibit different chondrogenic and osteogenic differentiation potential. Stem Cell Rev Rep. 2011; 7:64-76.

Reya T, Clevers H. Wnt signalling in stem cells and cancer. Nature. 2005; 434:843-850. [PubMed: 15829953]

Safford KM, Hicok KC, Safford SD, Halvorsen YD, Wilkison WO, Gimble JM, Rice HE. Neurogenic differentiation of murine and human adipose-derived stromal cells. Biochem Biophys Res Commun. 2002; 294:371-379. [PubMed: 12051722]

Salero E, Hatten ME. Differentiation of ES cells into cerebellar neurons. Proc Natl Acad Sci USA. 2007; 104:2997-3002. [PubMed: 17293457]

Sánchez-Sánchez AV, Camp E, Leal-Tassias A, Mullor JL. Wnt signaling has different temporal roles during retinal development. Dev Dyn. 2010; 239:297-310. [PubMed: 20014102]

Szanya V, Ermann J, Taylor C, Holness C, Fathman CG. The subpopulation of CD4+ CD25+ splenocytes that delays adoptive transfer of diabetes expresses L-selectin and high levels of CCR7. J Immunol. 2002; 169:2461-2465. [PubMed: 12193715]

Toledo EM, Colombres M, Inestrosa NC. Wnt signaling in neuroprotection and stem cell differentiation. Prog Neurobiol. 2008; 86:281-296. [PubMed: 18786602]

Tomita M, Mori T, Maruyama K, Zahir T, Ward M, Umezawa A, Young MJ. A comparison of neural differentiation and retinal transplantation with bone marrow-derived cells and retinal progenitor cells. Stem Cells. 2006; 24:2270-2278. [PubMed: 17008430]

Tsai PJ, Wang HS, Shyr YM, Weng ZC, Tai LC, Shyu JF, Chen TH. Transplantation of insulinproducing cells from umbilical cord mesenchymal stem cells for the treatment of streptozotocininduced diabetic rats. J Biomed Sci. 2012; 30:19-47.

Van Raay TJ, Moore KB, Iordanova I, Steele M, Jamrich M, Harris WA, Vetter ML. Frizzled 5 signaling governs the neural potential of progenitors in the developing Xenopus retina. Neuron. 2005; 46:23-36. [PubMed: 15820691]

Volarevic V, Arsenijevic N, Lukic ML, Stojkovic M. Concise review: mesenchymal stem cell treatment of the complications of diabetes mellitus. Stem Cells. 2011; 29:5-10. [PubMed: 21280154]

Wang JF, Wang LJ, Wu YF, Xiang Y, Xie CG, Jia BB, Harrington J, McNiece IK. Mesenchymal stem/progenitor cells in human umbilical cord blood as support for ex vivo expansion of CD34(+) hematopoietic stem cells and for chondrogenic differentiation. Haematologica. 2004; 89:837-844. [PubMed: 15257936]

Wei LC, Ding YX, Liu YH, Duan L, Bai Y, Shi M, Chen LW. Low-dose radiation stimulates Wnt/ beta-catenin signaling, neural stem cell proliferation and neurogenesis of the mouse hippocampus in vitro and in vivo. Curr Alzheimer Res. 2012; 9:278-289. [PubMed: 22272614] 
Yang Z, Li K, Yan X, Dong F, Zhao C. Amelioration of diabetic retinopathy by engrafted human adipose-derived mesenchymal stem cells in streptozotocin diabetic rats. Graefes Arch Clin Exp Ophthalmol. 2010; 248:1415-1422. [PubMed: 20437245] 

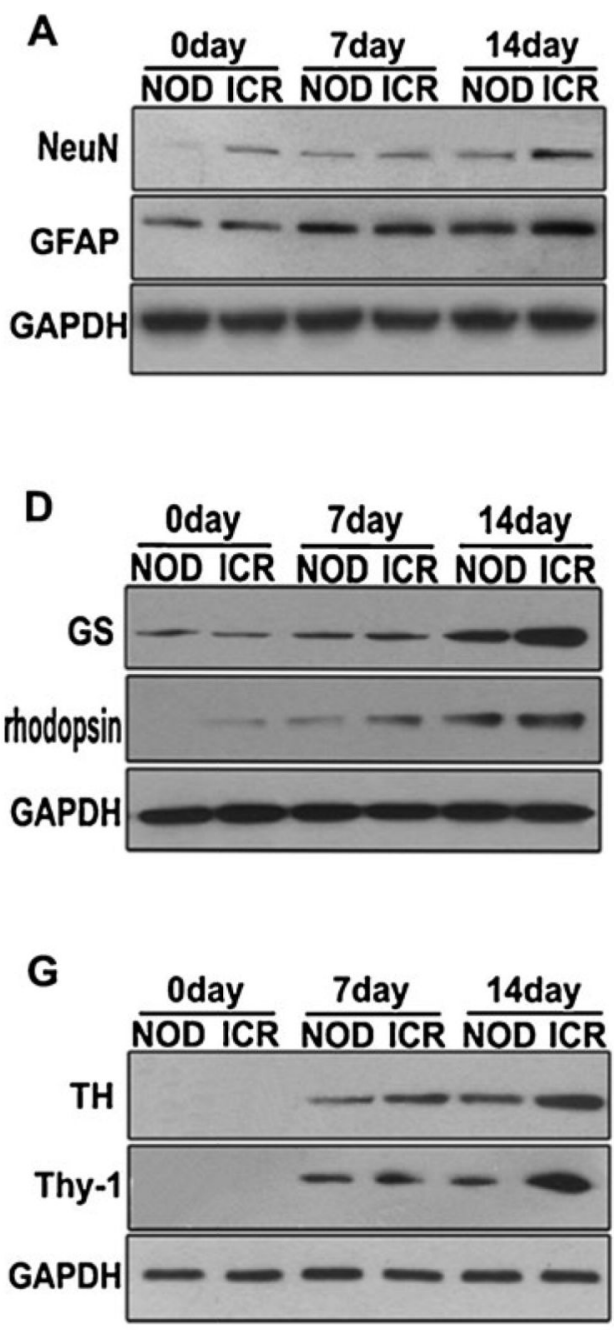
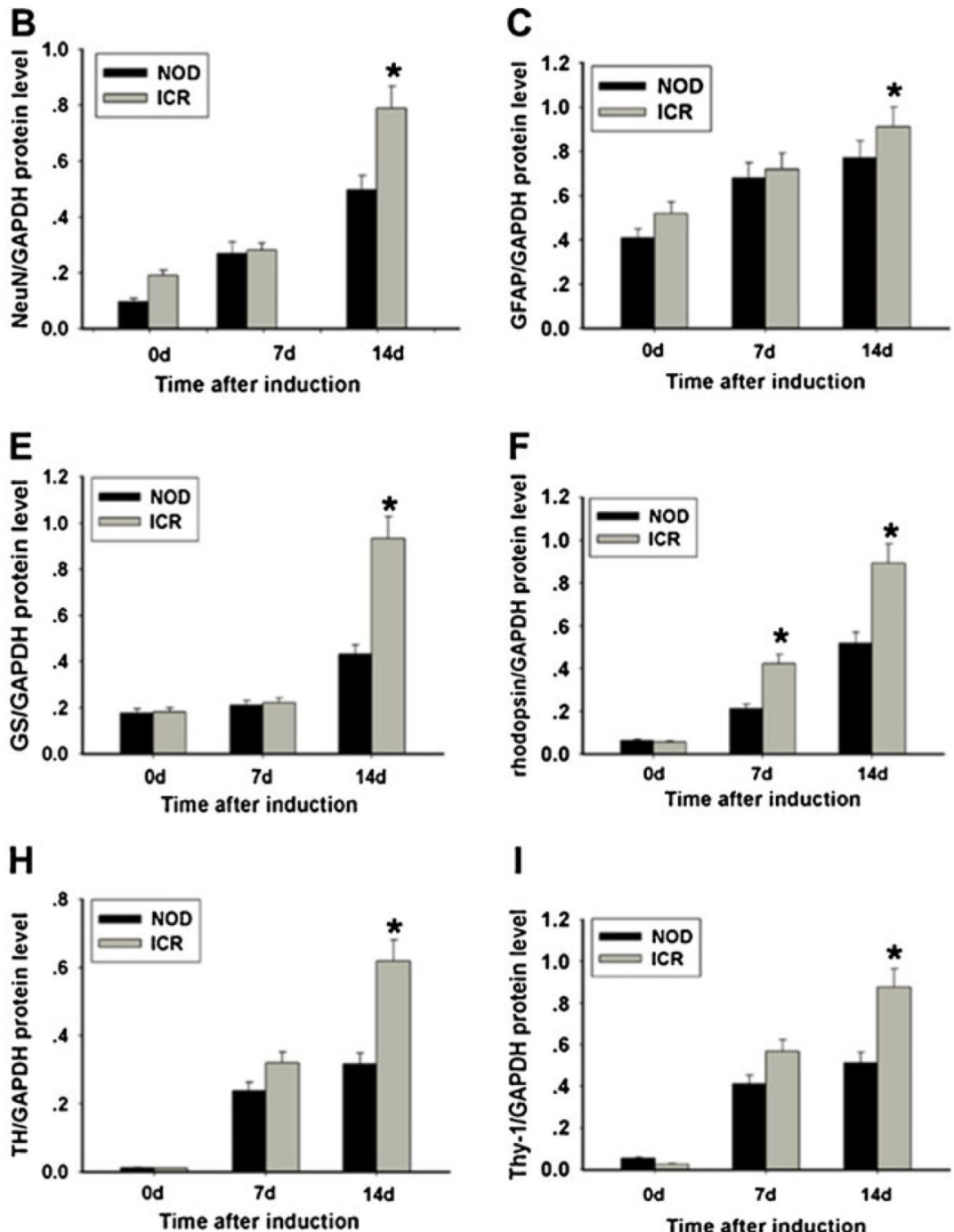

1

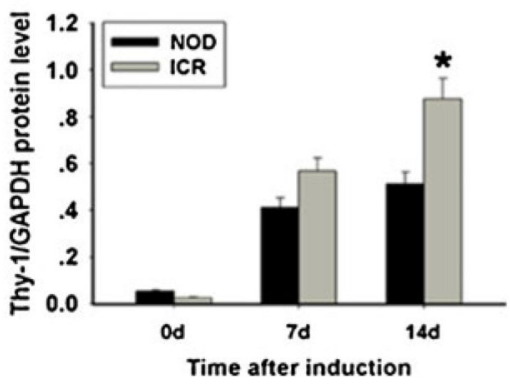

Fig. 1.

Analysis of retinal neuron-like differentiation potential between NOD-MSCs and ICR-

MSCs by Western blot. a Western blot analysis of GFAP and NeuN expressions. b Quantification of GFAP protein levels. c Quantification of NeuN protein levels. d Western blot analysis of TH and Thy-1 expressions. e Quantification of TH protein levels. f Quantification of Thy-1 protein levels. g Western blot analysis of GS and rhodopsin expressions. h Quantification of GS protein levels. i Quantification of rhodopsin protein levels. GAPDH was used as the internal control. The levels of these proteins were significantly decreased in the NOD-MSCs compared with that in ICR-MSCs after BDNF, NGF, and bFGF induction for 7 and 14 days $(* P<0.05 ; n=5)$ 

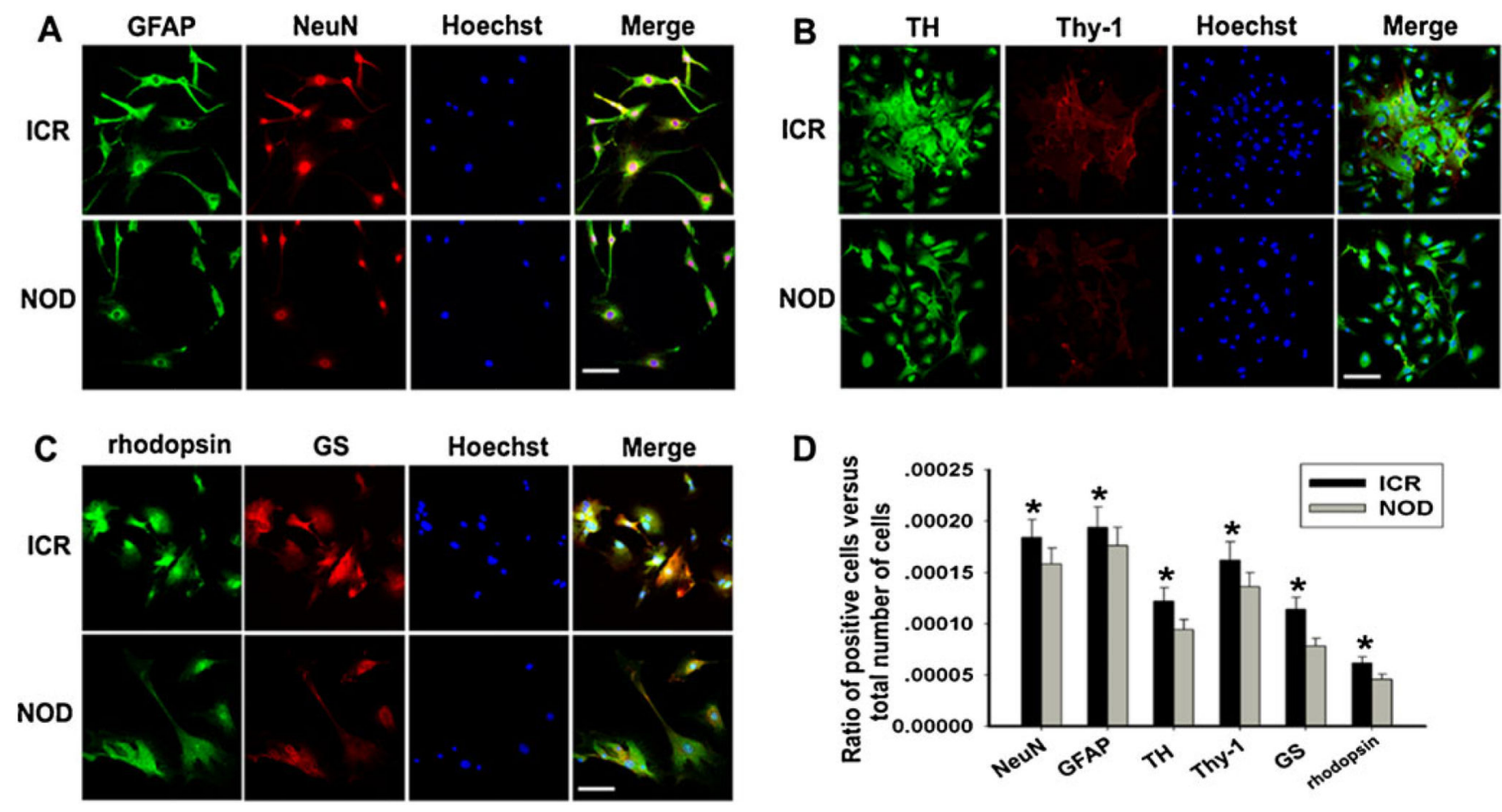

Fig. 2.

Analysis of retinal neuron-like differentiation potential between NOD-MSCs and ICRMSCs by immunofluorescence. a Immunofluorescence staining of GFAP (green) and NeuN (red). Blue Hoechst stain. b Immunofluorescence staining of TH (green) and Thy-1 (red). Blue Hoechst stain. c Immunofluorescence staining of GS (green) and rhodopsin (red). Blue Hoechst stain. The immunofluorescence staining of retinal neuron-like markers in the NODMSCs had a low intensity compared with the ICR-MSCs after induction for 14 days. Scale bar= $25 \mu \mathrm{m}$. d Quantitative evaluation of differentiated ratio: NOD-MSCs versus ICRMSCs. The ratio of positive cells versus total number of cells in the culture: comparison of NOD-MSCs and ICR-MSCs. In this study, GFAP-, NeuN-, TH-, Thy-1-, GS-, and rhodopsin-positive cells were counted 14 days after induction $(* P<0.05 ; n=5)$ 


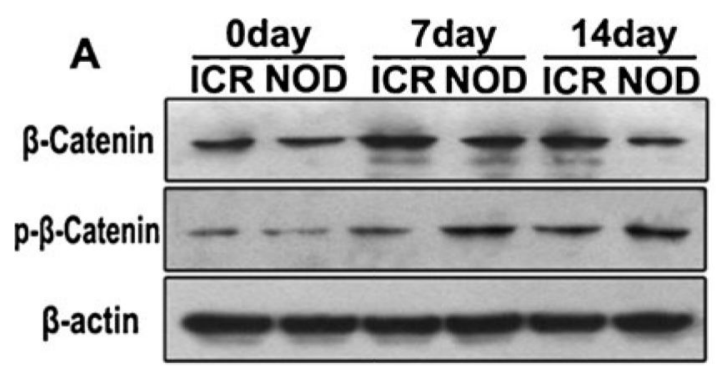

B

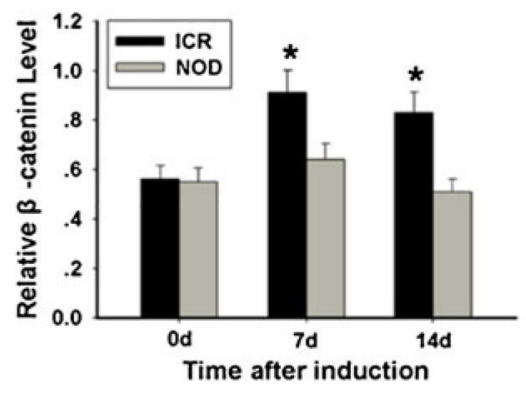

C

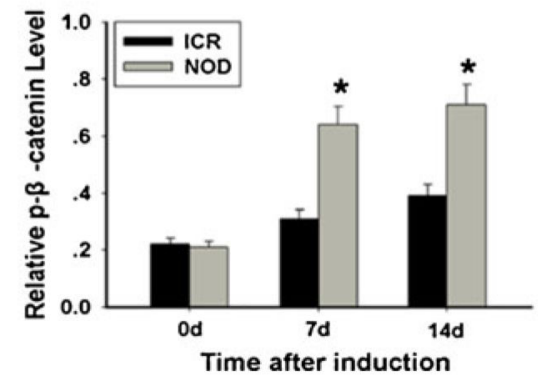

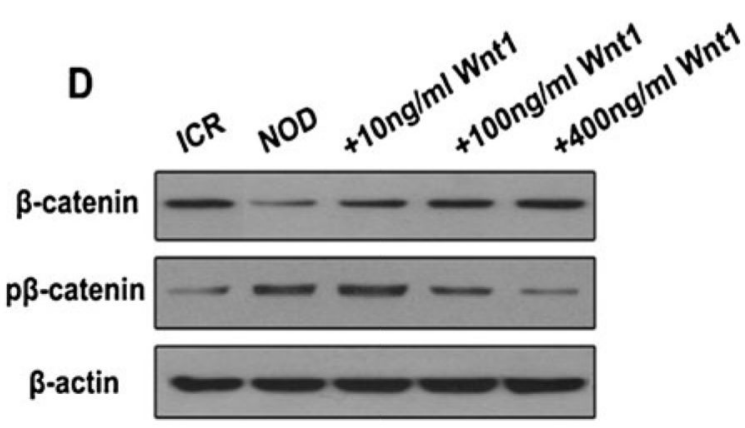

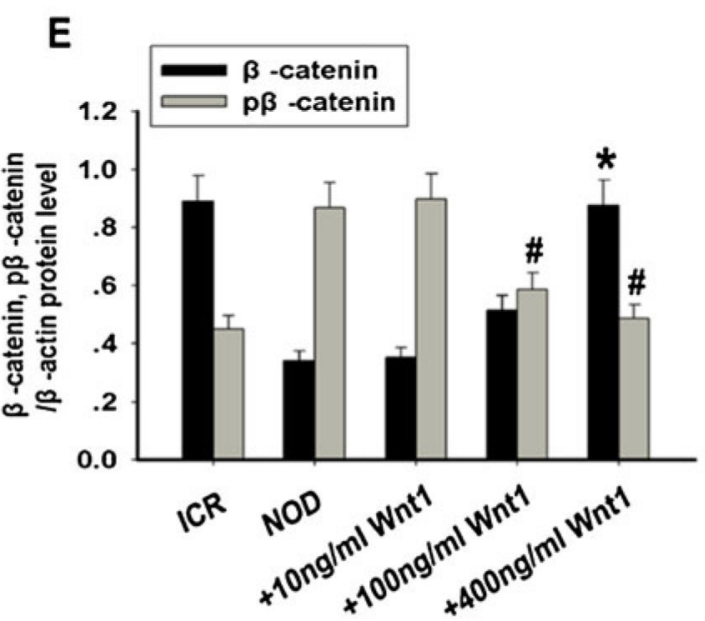

Fig. 3.

Analysis of the expressions of $\beta$-catenin and phosphorylated $\beta$-catenin. a Western blot analysis of $\beta$-catenin and phosphorylated $\beta$-catenin expressions. $\beta$-Actin was used as the internal control. b Quantification of $\beta$-catenin protein levels. $\mathbf{c}$ Quantification of phosphorylated $\beta$-catenin protein levels. At the 7th and 14th day, decreased expression of $\beta$ catenin and increased expression of phosphorylated $\beta$-catenin were clearly detected in the NOD-MSCs compared with that in the ICR MSCs $(* P<0.05 ; n=5)$. d Western blot analysis of $\beta$-catenin and phosphorylated $\beta$-catenin expressions in neural induction medium with recombinant human Wnt1 (10-400 ng/ml) for 14 days. e Quantification of $\beta$-catenin and phosphorylated $\beta$-catenin protein levels after treatment with Wnt1. Only treatment with high Wnt 1 concentrations (100 and $400 \mathrm{ng} / \mathrm{mL}$ ) significantly increased the expression of $\beta$ catenin and decreased the expression of phosphorylated $\beta$-catenin $\left({ }^{*} P<0.05,{ }^{\#} P<0.05 ; n=5\right)$ 

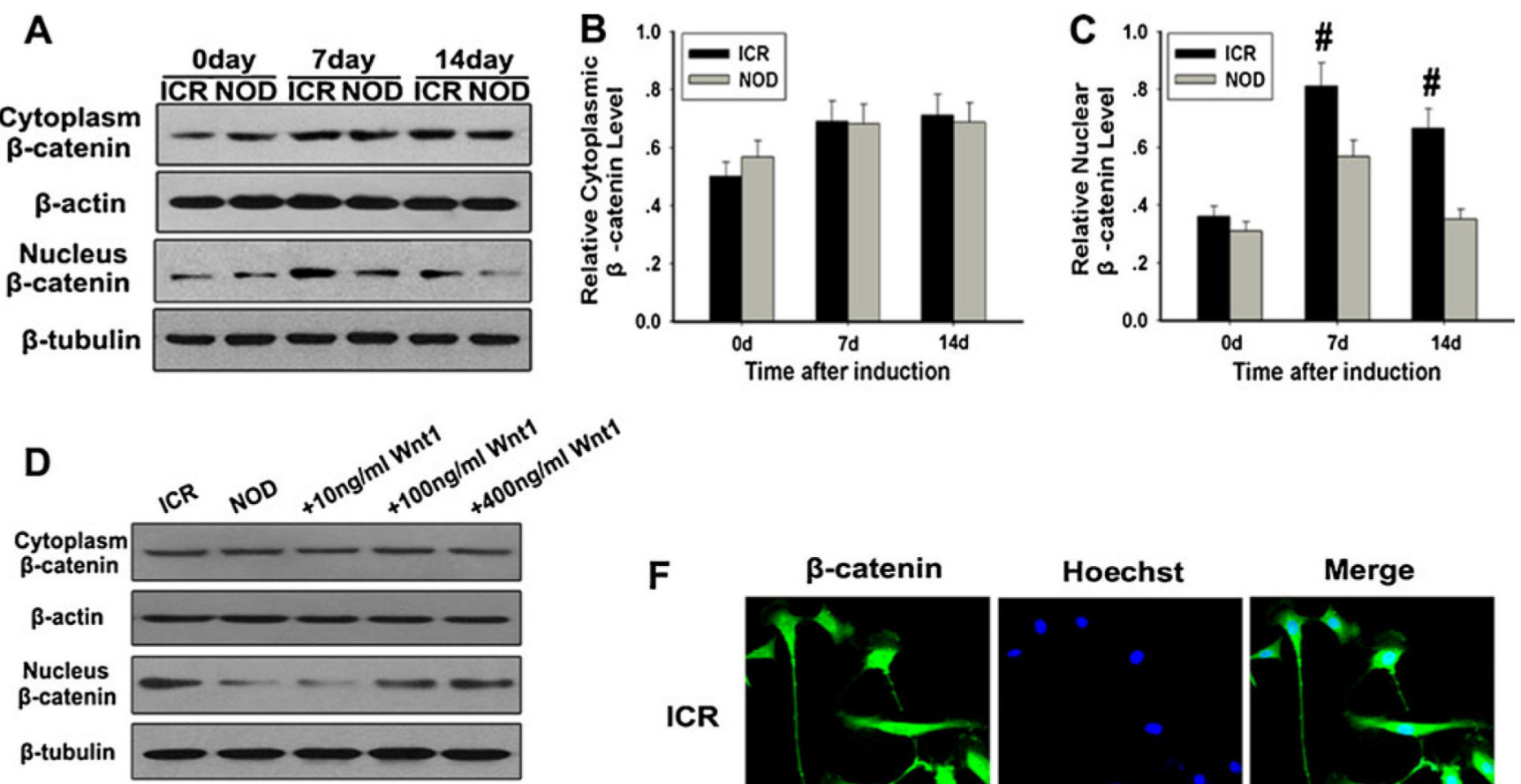

\section{E}

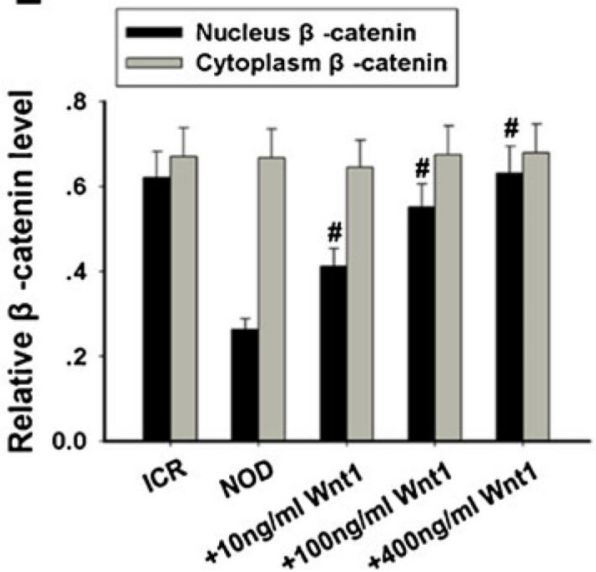

F
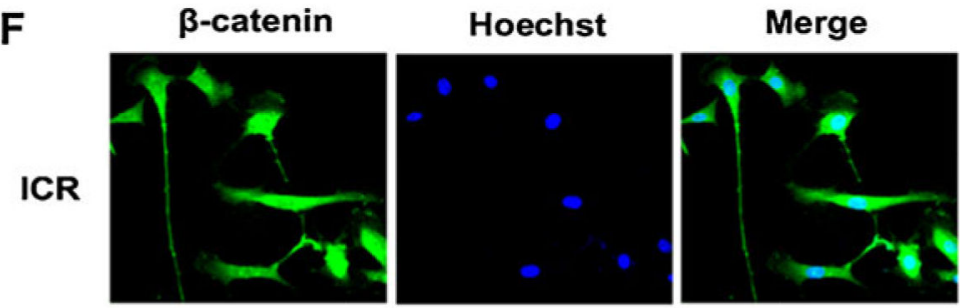

NOD
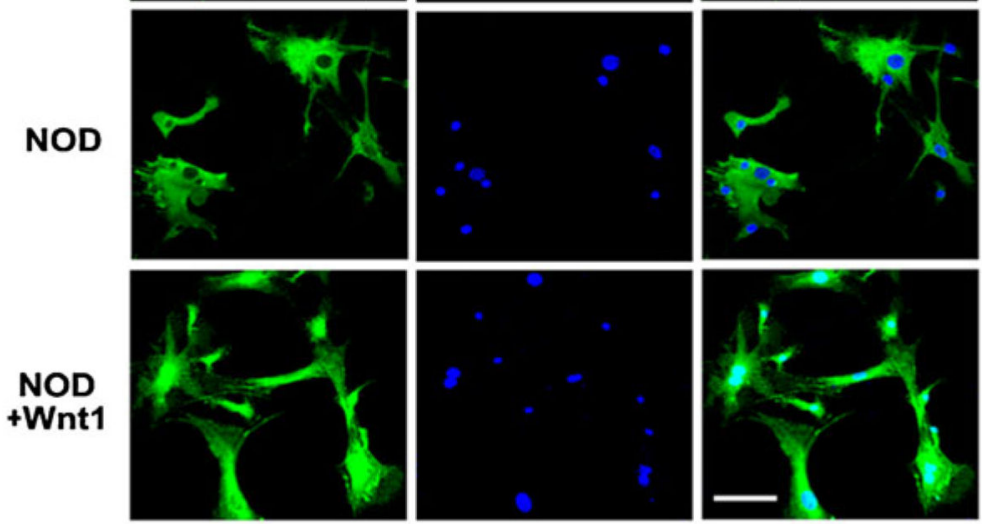

Fig. 4.

Analysis of the cytoplasmic and nuclear $\beta$-catenin in NOD-MSCs. a Western blot analysis of the cytoplasmic and nuclear $\beta$-catenin expressions after BDNF, NGF, and bFGF induction for 7 and 14 days. $\beta$-Actin was used as the internal control for the cytoplasmic proteins, whereas $\beta$-tubulin was used as the internal control for the nuclear proteins. b Quantification of the cytoplasmic $\beta$-catenin expressions after induction. $\mathbf{c}$ Quantification of the nuclear $\beta$ catenin expressions after induction. Total $\beta$-catenin in the nucleus was significantly lower in NOD-MSCs than in ICR-MSCs after BDNF, NGF, and bFGF treatment for 7 and 14 days. There was no change of total $\beta$-catenin in the cytoplasm between NOD-MSCs and ICRMSCs ( $\left.{ }^{\#} P<0.05 ; n=5\right)$. d Western blot analysis of the cytoplasmic and nuclear $\beta$-catenin expressions after treatment with Wnt1 (10-400 ng/ml). $\beta$-Actin was used as the internal control for the cytoplasmic proteins, whereas $\beta$-tubulin was used as the internal control for 
the nuclear proteins. e Quantification of the cytoplasmic and nuclear $\beta$-catenin protein levels after treatment with Wnt $1(10-400 \mathrm{ng} / \mathrm{ml})$. Wnt 1 concentrations $>100 \mathrm{ng} / \mathrm{mL}$ were sufficient to increase nuclear $\beta$-catenin expression. There was no change of total $\beta$-catenin in the cytoplasm of NOD-MSCs after different concentrations of Wnt $\left({ }^{\#} P<0.05 ; n=5\right)$. $\mathbf{f}$ Immunofluorescence staining of $\beta$-catenin. The immunofluorescence staining of $\beta$-catenin in the cellular nucleus of NOD-MSCs had a low intensity compared with that in the ICR-MSCs after treatment with $400 \mathrm{ng} / \mathrm{ml} \mathrm{Wnt} 1$, while the nuclear $\beta$-catenin expression significantly increased. Scale bar $=25 \mu \mathrm{m}$ 


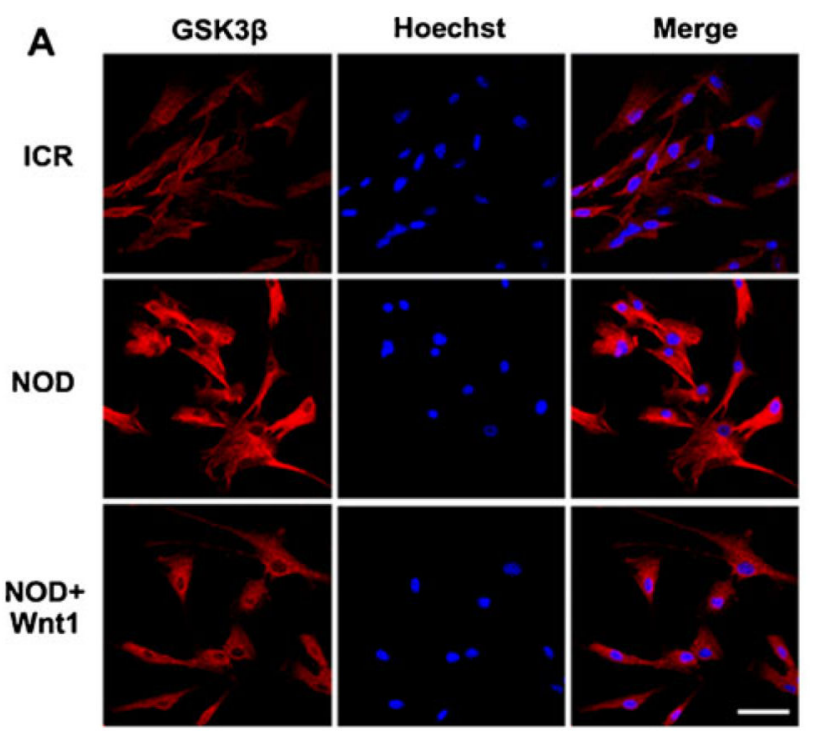

B

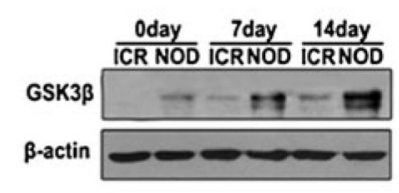

C

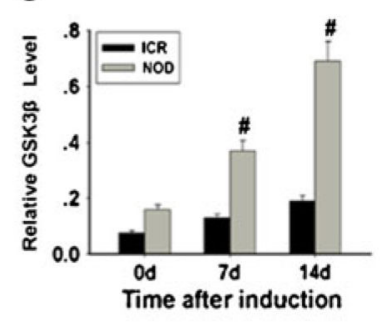

D
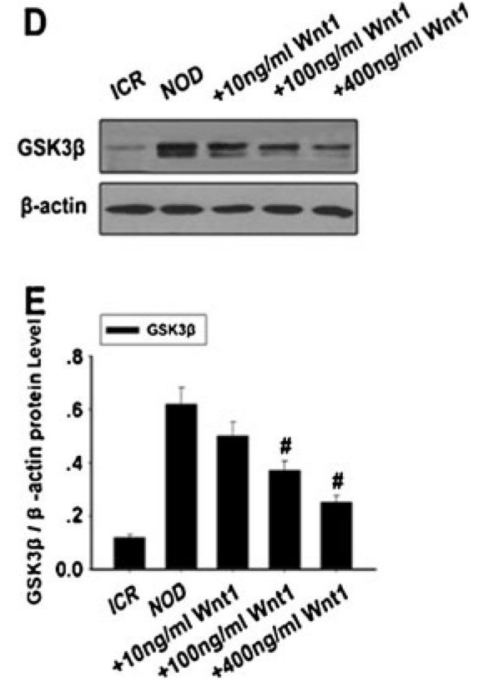

Fig. 5.

Analysis of GSK-3 $\beta$ expression in NOD-MSCs. a Immunofluorescence staining of GSK-3 Compared with that in the NOD-MSCs, GSK-3 $\beta$ expression was weak in the ICR-MSCs. However, after treatment with $400 \mathrm{ng} / \mathrm{ml}$ Wnt1, the GSK-3 $\beta$ expression decreased in NODMSCs. Red GSK-3 $\beta$, blue Hoechst. Scale bar $=25 \mu \mathrm{m}$. b Western blot analysis of GSK-3 $\beta$ expression. $\beta$-Actin was used as the internal control. $\mathbf{c}$ Quantification of GSK-3 $\beta$ protein levels. After BDNF, NGF, and bFGF treatment for 7 and 14 days, GSK-3 $\beta$ protein levels were significantly decreased in the NOD-MSCs compared with that of the ICR-MSCs ( $\left.{ }^{\#} P<0.05 ; n=5\right)$. d Western blot analysis of the GSK-3 $\beta$ expressions after treatment with Wnt $1(10-400 \mathrm{ng} / \mathrm{ml})$. e Quantification of the GSK-3 $\beta$ protein levels after treatment with Wnt $1(10-400 \mathrm{ng} / \mathrm{ml})$. Wnt 1 concentrations $>100 \mathrm{ng} / \mathrm{mL}$ were sufficient to decrease GSK-3 $\beta$ expression ( ${ }^{\#} P<0.05 ; n=5$ ) 

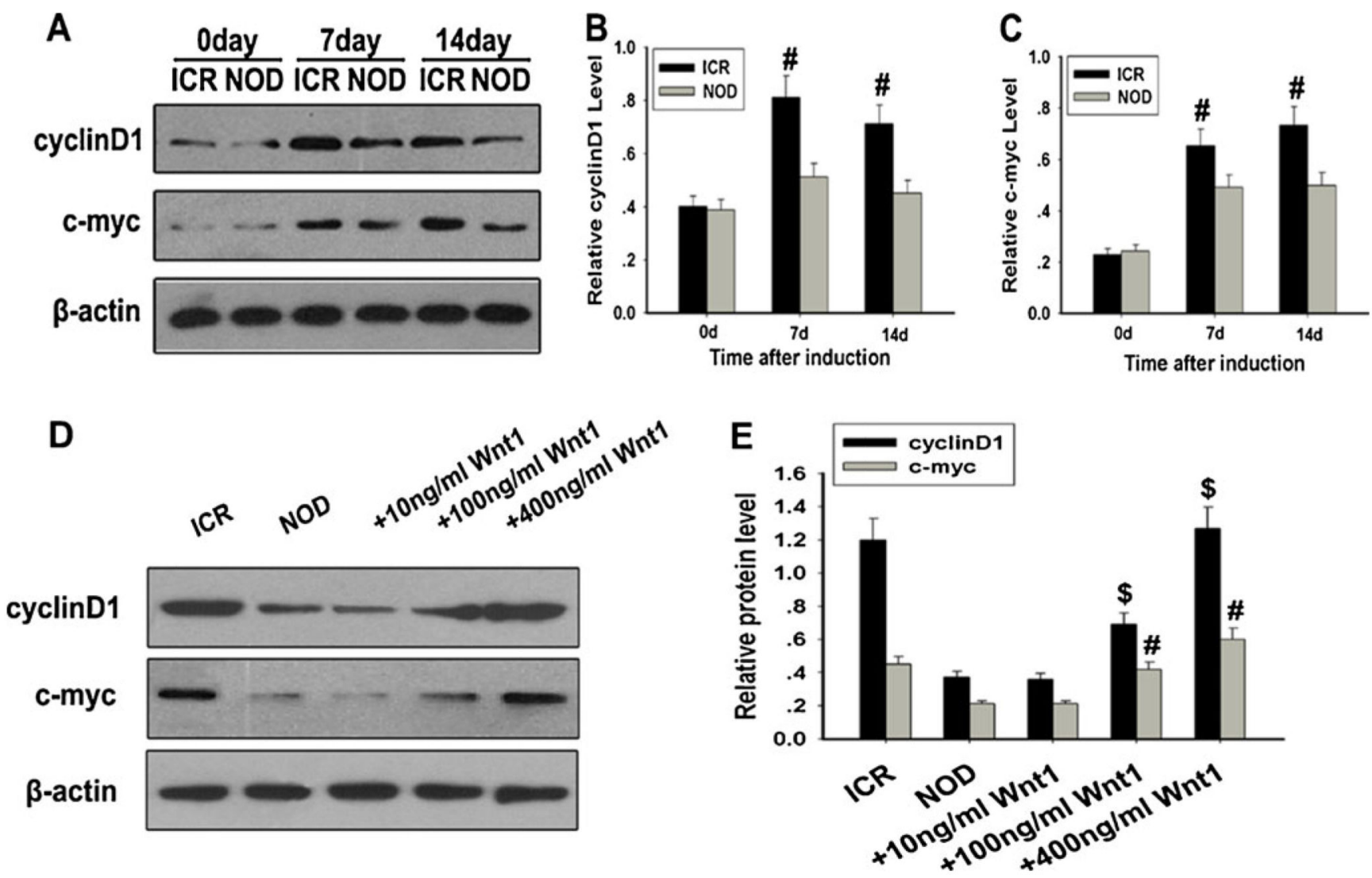

Fig. 6.

Analysis of c-myc and cyclin D1 expressions in NOD-MSCs. a Western blot analysis of c$m y c$ and cyclin D1 expressions. $\beta$-Actin was used as the internal control. b Quantification of cyclin D1 protein levels. c Quantification of c-myc protein levels. After BDNF, NGF, and bFGF treatment for 7 and 14 days, c-myc and cyclin D1 protein levels were significantly decreased in NOD-MSCs compared with the ICR-MSCs ( $\left.{ }^{\#} P<0.05 ; n=5\right)$. d Western blot analysis of $c$-myc and cyclin D1 expressions after treatment with Wnt1 (10-400 ng/ml). e Quantification of c-myc and cyclin D1 protein levels after treatment with Wnt1 (10-400 ng/ $\mathrm{ml})$. Wnt 1 concentrations $>100 \mathrm{ng} / \mathrm{mL}$ were sufficient to increase c-myc and cyclin D1 expressions in NOD-MSCs $\left({ }^{\#} P<0.05,{ }^{\$} P<0.05 ; n=5\right)$ 

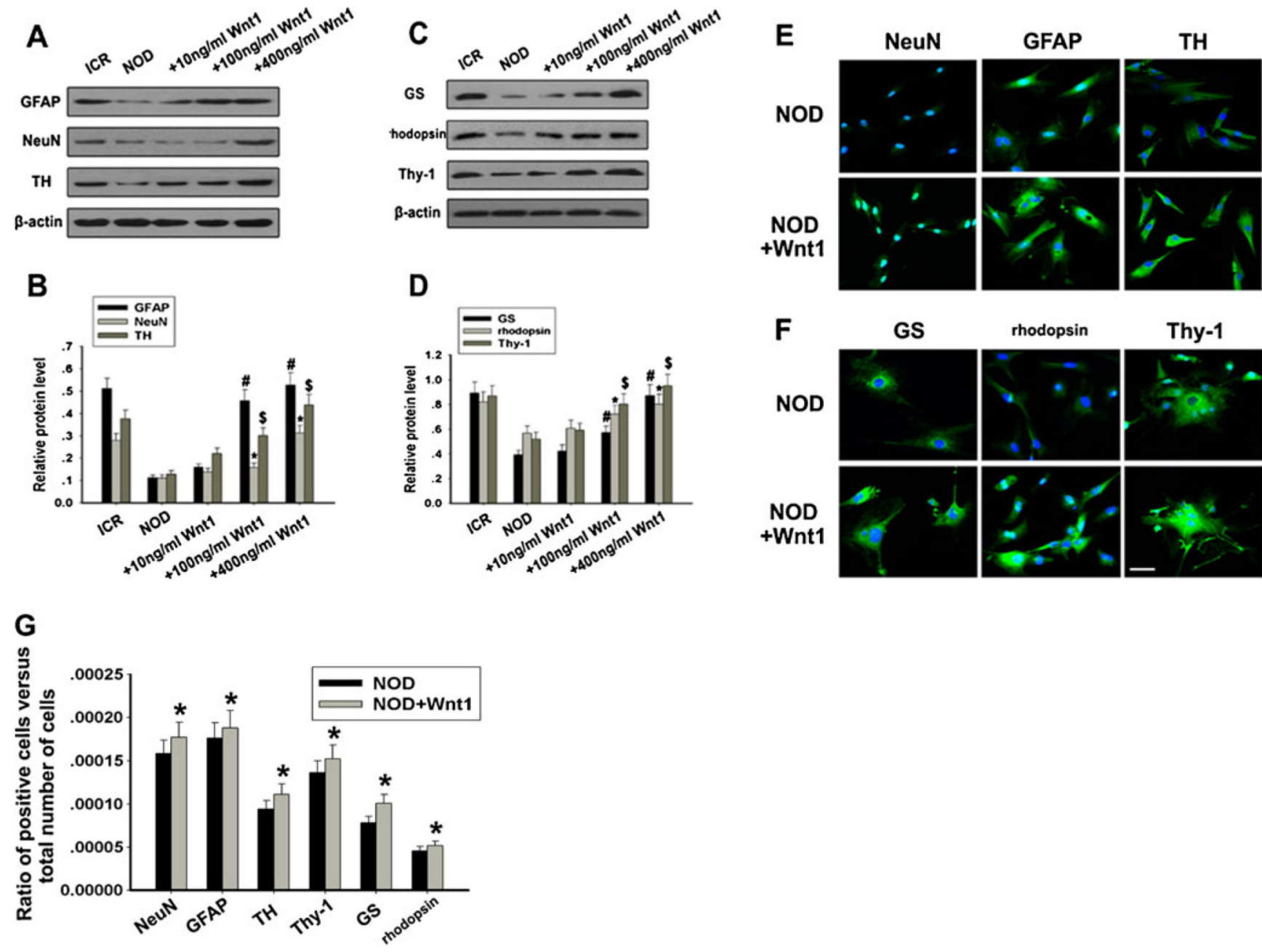

Fig. 7.

Effects of Wnt1 on NOD-MSCs retinal neuron-like differentiation. a Western blot analysis of GFAP, NeuN, and TH expressions after treatment with Wnt1 (10-400 ng/ml). b Quantification of GFAP, NeuN, and TH protein levels after treatment with Wnt1 (10-400 $\mathrm{ng} / \mathrm{ml})$. c Western blot analysis of Thy-1, GS, and rhodopsin expressions after treatment with Wnt1 (10-400 ng/ml). $d$ Quantification of Thy-1, GS, and rhodopsin protein levels after treatment with Wnt1 (10-400 ng/ml). After neural induction with recombinant human Wnt1 (10-400 ng/ml) for 14 days Wnt 1 concentrations $>100 \mathrm{ng} / \mathrm{mL}$ were sufficient to increase GFAP, NeuN, TH, Thy-1, GS, and rhodopsin expressions in NOD-MSCs $\left({ }^{*} P<0.05,{ }^{\#} P<0.05,{ }^{\$} P<0.05 ; n=5\right)$. e Immunofluorescence staining of GFAP (green), NeuN (green), and TH (green). Blue Hoechst stain. f Immunofluorescence staining of Thy-1 (green), GS (green), and rhodopsin (green). Blue Hoechst stain. g Quantitative evaluation of differentiated ratio after treatment with recombinant human Wnt1 (10-400 ng/ml) for 14 days: NOD-MSCs versus ICR-MSCs. The ratio of positive cells versus total number of cells in the culture: comparison of NOD-MSCs and ICR-MSCs. In this study, GFAP-, NeuN-, TH-, Thy-1-, GS-, and rhodopsin-positive cells were counted 14 days after induction 
$\left({ }^{*} P<0.05 ; n=5\right)$. After treatment with $400 \mathrm{ng} / \mathrm{mL}$ Wnt 1 , the levels of these proteins significantly increased in NOD-MSCs. Scale bar $=25 \mu \mathrm{m}$ 